\title{
INVISIBILIDAD INDÍGENA EN LA MEMORIA DE LA COLONIZACIÓN RECIENTE DE PARAGUAY
}

\author{
ANDRESSA SZEKUT ${ }^{1}$ \\ UNIOESTE, BRASIL \\ JORGE EREMITES DE OLIVEIRA ${ }^{2}$ \\ UFPEL, BRASIL
}

\begin{abstract}
RESUMEN: En este artículo se hace una reflexión crítica del proceso de colonización reciente ocurrido en Paraguay durante el gobierno dictatorial del General Alfredo Stroessner (19541989) y la invisibilidad creada sobre comunidades indígenas establecidas en la región Oriental del país, con enfoque en el Distrito de Santa Rita, Departamento de Alto Paraná. El estudio fue realizado por medio de investigación bibliográfica y documental y a través de trabajo de campo etnográfico. En el texto se presentan datos que muestran la presencia indígena en Paraguay y se analizan discursos de migrantes brasileños, los cuales producen una invisibilidad en relación a la presencia de pueblos originarios en la porción oriental del Paraguay, aunque los mismos estén presentes en la región desde antes de la colonización oficial y alli permanecen hasta el presente.
\end{abstract}

PALABRAS-ClAVE: Pueblos Indigenas en Paraguay, Colonización, Historia Indigena, Memoria.

\begin{abstract}
In this article a critical reflection of the recent colonization process occurred in Paraguay during the dictatorial government of General Alfredo Stroessner (1954-1989) and the invisibility created on indigenous communities established in the Eastern region of the Country, focusing on the District of Santa Rita, Department (State) of Alto Paraná. The study was conducted through bibliographic and documentary research and through ethnographic fieldwork. The text presents data that show the indigenous presence in Paraguay and discusses the discourses of Brazilian migrants, which produce an invisibility in relation to the presence of native peoples in the Eastern portion of Paraguay, although they are present in the region from before the official colonization and there they remain until the present.
\end{abstract}

KEYWORDS: Indigenous Peoples in Paraguay, Colonization, Indigenous History, Memory.

\footnotetext{
${ }^{1}$ Professora dos cursos de Turismo e Hotelaria (Universidade Estadual do Oeste do Paraná, Brasil) e Coordenadora de Pesquisa do Instituto Polo Internacional Iguaçu. E-mail: andressaszekut@gmail.com

${ }^{2}$ Professor do curso de Antropologia e do Programa de Pós-Graduação em Memória Social e Patrimônio Cultural (Universidade Federal de Pelotas, Brasil). E-mail: eremites.br@gmail.com
} 


\section{Introducción}

La Tierra Guaraní, como se acostumbra llamar a Paraguay, muestra durante el transcurso de su historia actos de violencia contra las poblaciones indígenas en curiosa contradicción con esa denominación. La situación de antigua colonia española, la intervención jesuítica y también portuguesa fueron apenas el inicio de un largo proceso de sistemática violación de derechos de los pueblos originarios en el actual territorio nacional de Paraguay. Durante toda su historia, desde el siglo XVI con el inicio del encuentro colonial hasta el tiempo presente, fueron recurrentes los hechos de violencia física y simbólica contra los indígenas quienes continúan en una situación marcada por la colonización, inicialmente europea y euroamericana después.

Este artículo presenta reflexiones sobre el tratamiento dado a los indígenas en Paraguay, especialmente los Aché (Guayakí) y Mbya, ambos de habla guaraní, desde el siglo XX hasta la actualidad. El estudio enfatiza a las acciones durante el gobierno dictatorial del general Alfredo Stroessner (1954-1989) y tiene como base la construcción de una imagen de vacío demográfico de gran parte territorio nacional. El análisis muestra una situación histórica marcada por el colonialismo interno (GONZÁLEZ CASANOVA, 2002 [1963]; CARDOSO DE OLIVEIRA, 1978; PACHECO DE OLIVEIRA, 1988) generador de la marginalización que invisibiliza y no reconoce efectivamente a los indígenas como sujetos de derecho en el país. Se contextualiza esta situación a partir de la bibliografía consultada y del trabajo de campo desarrollado durante 2015 en Santa Rita Departamento de Alto Paraná/Paraguay, municipio formado durante el proceso de colonización reciente - en las décadas 1970 y 1980 . También aportan al trabajo estudios realizados, en los últimos años, y publicados en revistas científicas de Brasil (vide SZEKUT e EREMITES DE OLIVEIRA, 2015, 2016, 2017).

\section{Indígenas en Paraguay y la colonización reciente}

El actual territorio de la República del Paraguay está dividido por los ríos Paraguay y Paraná en dos regiones: occidental y oriental; las cuales conforman, geográfica, histórica y socialmente, espacios muy diferentes. La Oriental, cuenca del río Paraná, era en gran parte compuesta por el bioma Mata Atlántica; la historia de la ocupación territorial lo muestra con una mayor concentración poblacional relativa, fruto de un clima ameno y suelo apto a la agricultura. Ya en la región Occidental, cuenca del río Paraguay, predomina el bosque tropical seco, típico del bioma Chaco. Y a su vez, puede dividirse en el Ilamado Chaco paraguayo y el Pantanal, alternativamente compuestos por zonas desérticas y otras inundadas por largos períodos - intercalando lluvia y sequia -; debido a estas características, tanto climáticas cuanto geográficas, se la identificó como desfavorable a la colonización y posee baja densidad poblacional relativa. 
En ese espacio mesopotámico que delimita la totalidad del territorio paraguayo habitan, desde tiempo inmemorial, indígenas de diferentes etnias esparcidas en un espacio sin fronteras rígidas y transnacional, si contemplamos que penetra los actuales Estados Nacionales vecinos. Estos indígenas sufrieron durante el periodo de colonización diferentes formas de intervención de sus territorios y culturas que continúan hasta hoy. Muchas comunidades fueron casi exterminadas por los diferentes tipos de apropiación territorial. Primero por el establecimiento de las colonias - española y portuguesa - y después por la dinámica territorial evidenciada por el actual mapa económico y división administrativa de la región.

Según el III0 Censo Nacional de Población y Viviendas para Pueblos Indígenas 2012 (DGEEC, 2012), actualmente existen en Paraguay 19 pueblos indígenas distribuidos en cinco familias lingüísticas (Tabla 1). Habitan 493 comunidades y 218 aldeas o barrios - totalizando 711 núcleos poblacionales - diseminados en los 13 departamentos del país y Asunción, ciudad capital. En este censo un total de 117.150 personas declaran pertenecer a alguna de las parcialidades indígenas existentes en el país, como parte de la población paraguaya total de algo menos de 6,5 millone de habitantes (DGEEC, 2012). Es importante mencionar, los números lanzados por los censos en el país no son completamente confiables por los criterios y metodología utilizados, no obstante, sirven para establecer una estimativa.

Tabla 1: Pueblos indígenas divididos por familias lingüísticas.

\begin{tabular}{|l|l|}
\hline Família Lingüística & Pueblos \\
\hline Guarani & $\begin{array}{l}\text { Pai Tavyterã, Avá Guaraní (Chiripa), Mbyá Guaraní, Aché (Guayaki), Guaraní Nandeva (Tapieté), } \\
\text { Guaraní ocidental (Guarayo) }\end{array}$ \\
\hline Maskoy & Sanapaná, Angaité, Guaná, Toba Maskoy, Enlhet Norte y Enxet Sur (Lengua) \\
\hline Zamuko & Ybytoso (Chamacoco), Ayoreo, Tomárãho \\
\hline Mataco Mataguayo & Nivaclé (Chulupi), Maká, Manjui (Chorotí) \\
\hline Guaicurú & Qom \\
\hline
\end{tabular}

Fuente: Tabla elaborada por los autores a partir de datos del III Censo Nacional de Población y Viviendas para Pueblos Indígenas (DGEEC, 2012).

Para sus realizadores (DGEEC), el censo indígena se realiza "con el afán de seguir promoviendo la visibilidad étnica, cultural y lingüística de los pueblos indígenas existentes en el Paraguay". En ese contexto, se indica que los pueblos indígenas del país participaron de un censo técnicamente comparable por primera vez en 1981, luego en el 2002 y, por último, el de 2012 en pauta; evidenciando que apenas recientemente se los reconoce y legitima como habitantes originales del territorio nacional. Se percibe de esta forma una semejanza con lo apuntado por Guerrero (1998) sobre una lógica de la igualdad de la sociedad ecuatoriana la cual, dice, no ser válida para las comunidades indígenas percibidas y tratadas de forma diferente en ese país. Guerrero (1998) indica un fenómeno de invisibilización de las poblaciones indígenas en la 
esfera pública y política durante la construcción de la ciudadanía - en el siglo XIX - y la describe como construcción de un campo de dominación que practica la exclusión de poblaciones nativas u originales. Análogamente, la inexistencia de una cuantificación confiable de los indígenas en Paraguay muestra un campo de dominación colonialista que excluye e invisibiliza esas parcialidades originarias, violando sus derechos, al no considerar sus miembros como sujetos de derecho en el país.

Borgognon (1968) expone que, hasta fines de la década de 1960, el sujeto indígena en Paraguay estaba marginado: no estaba inscripto en el Registro del Estado Civil de las personas, no votaba y no pagaba impuestos en el país. Esta realidad de exclusión del indígena como sujeto de derecho en el país no ha cambiado. A pesar de Paraguay, en el capítulo $\checkmark$ de la Constitución Nacional (1992), reconocer los pueblos indígenas y sus derechos; y en el artículo 46 establecer la igualdad de las personas con la no discriminación; y haber ratificado, en el 2000, la Convención Internacional sobre la Eliminación de todas las Formas de Discriminación Racial, el país exhibe muchos casos de discriminación y marginalización de pueblos indígenas. Ellos continúan al margen de la sociedad, sin tener sus derechos básicos o elementares atendidos ${ }^{3}$.

Además de los cambios en la Constitución Nacional, es relevante recordar que Paraguay, así como los demás países de América Latina, ha practicado políticas indigenistas de asimilación de pueblos originarios, a partir del proyecto republicano de national building con la idea del liberalismo político, heredada de Europa, de construir una ciudadanía culturalmente homogénea. Esto es evidenciado en lo que establece la Constitución Paraguaya de 1870, promulgada después de la Guerra de la Triple Alianza (1864-1870), en su Capítulo VIII, dedicado a las atribuciones del Congreso, dice: "Proveer a la seguridad de las fronteras; conservar el trato pacífico con los indios y promover la conversión de ellos al cristianismo y a la civilización" (Art. 72, Inc.13). Este dispositivo constitucional legitimaba la discriminación y aculturación de los indígenas y el Estado no les reconocía sus territorios y otros derechos. Queda evidente, pues, que las declaraciones de ciudadanía universal para las poblaciones de la República del Paraguay no contemplan a los pueblos originarios, al menos en su estado "salvaje o bárbaro", como muchas personas piensan y defienden.

Lo que se construyó como imagen homogénea de sociedad paraguaya fue el del mestizaje entre españoles e indígenas, ocurrida durante el período colonial, desde el siglo XVI hasta el XIX. En una idealización de sociedad blanca y mestiza, el indígena "no civilizado" (no aculturado, ni integrado) no comparte el derecho de ser ciudadano paraguayo. Independiente desde 1811, Paraguay pasó de colonia española a una situación de colonización interna ejercida por una élite

\footnotetext{
${ }^{3}$ Por ejemplo, en el sitio web de la Justicia Electoral de la República de Paraguay, se puede ver el "Proyecto: Fortalecimiento de la participación electoral de los pueblos Indígenas del Paraguay". Justamente desarrollado por todavía seguir con prácticas desiguales y discriminatorias para con sus ciudadanos, al no contemplar a los indígenas con derechos básicos como el del Registro Civil, lo que posibilita alcance a otros derechos. Vide link https://tsje.gov.py/pueblos-indigenas.html; acceso en 20/ago./2017. 
criolla y la nación fue construida sobre los intereses de este mismo grupo minoritario privilegiado. Como base para la imagen colectiva de su sociedad, se utilizaron precedentes históricos que caracterizaron el territorio. Entre ellos, elementos de la cultura guaraní, como lenguaje y culinaria, purificándola con el filtro de la modernidad civilizada y no contemplando su totalidad cultural. En este caso, el mestizaje cuando "acultura" el indio es visto como algo bueno y exitoso al proyecto de construcción de la identidad nacional; de lo contrario, es visto como algo malo o fracasado por las élites nacionales.

Así, al hablar de indígenas en Paraguay es necesario comprender toda una situación histórica de irrespeto de los derechos de esos pueblos. El país que tiene como una de sus lenguas oficiales el guaraní, idioma de origen indígena, y que buscó construir una imagen de "Nación Guaraní", explotó a los indígenas de su territorio e históricamente los excluye de las relaciones de producción y socioculturales. Makaran (2014), en su libro sobre el nacionalismo y sus mitos en Paraguay, muestra que en la construcción de la nación se usa de un discurso de "raza guaraní" y "tierra guaraní" como mito de origen atado al imaginario indígena pero que no pasa de retórica, pues los indígenas en la práctica son renegados por la población. En sus propias palabras:

Mientras que el discurso nacionalista subraya las raíces guaraníes del mestizo paraguayo y éste con orgullo alardea ser descendiente de la gloriosa raza de guerreros, la sociedad paraguaya suele despreciar al indígena actual, considerado un estorbo para el progreso y un vestigio arcaico, sentenciado por la selección natural a perecer. La situación actual del indio en Paraguay parece desmentir, o por lo menos complejizar, el mito del mestizaje paraguayo (MAKARAN, 2014, p.181).

Gaya complementa: "[...] la sociedad nacional vive física y moralmente separada de las poblaciones indígenas guaraníes actuales, al grado de no considerarlas compatriotas ni siquiera humanas" (GAYA, 2014 , p.205). Esta autora muestra cómo los indígenas, aun teniendo sus valores utilizados para la construcción de un imaginario social nacional, son rechazados por la sociedad paraguaya. Esta perspectiva muestra las relaciones de poder existentes en el país y denuncia los abusos históricos sobre las poblaciones originales.

Este tratamiento de los pueblos indígenas en el Paraguay es denunciado por diferentes estudiosos. Borgognon (1968) habla de la necesidad de reconocer a las comunidades indígenas del país dejadas, desde la independencia, a su suerte. El autor apunta, históricamente "para el común de la gente y también en las esferas oficiales, hablar de indio era sinónimo de incapacidad integral" o tutela, no reconociéndolos como parte de la sociedad paraguaya contemporánea.

La masa aborigen es una herencia que nadie intentó administrarla, haciendo que ella fuera también un 
complemento más de nuestra comunidad paraguaya. Siempre fue para los más generosos, una mera fuente sentimental ligándonos a nuestros antecesores, por los vínculos de sangre, idioma y algunas características anímicas espirituales, que persiste en el hombre paraguayo (BORGOGNON, 1968, p.344).

Meliá y Münzel (1971) a su vez exponen como innúmeras comunidades indígenas ocupaban de forma inmemorial todo el territorio de la gran cuenca platina (comprendida hoy por parte de las actuales fronteras nacionales de Paraguay, Argentina, Bolivia, Brasil y Uruguay) y que fueron expulsas o exterminadas, en diferentes momentos y formas, por los colonizadores españoles y portugueses y sus sucesores, y luego por la colonización reciente. Sus datos desmienten el discurso de vacío demográfico que se construye, principalmente, sobre la región Oriental.

\section{Violencia y expropiación reciente de territorios indígenas}

Este tema se estudia con profundidad en el libro Los Aché del Paraguay: Discusión de un Genocidio (PARELLADA e BELDÍ DE ALCÁNTARA, 2008), con contribuciones de Mark Münzel, estudioso responsable por la denuncia internacional de ese genocidio. El libro muestra la acción contra indígenas a partir de una compilación de textos que reflexionan, especialmente, sobre el intento de exterminio de los indígenas Aché en la región Oriental del Paraguay. Exhiben que sucedió, principalmente, entre los años 1960 y 1970, e indican que fue una acción deflagrada por el gobierno militar, pero también por civiles, con la garantía de impunidad. Estos textos explicitan como motivación de ese genocidio los intereses económicos sobre el territorio, el cual se pensaba como área de expansión agro-ganadera del país. Esto sucedió concomitante a la acción de empresas colonizadoras, las cuales trabajaban en consonancia con los intereses del Estado.

La violencia contra los pueblos originarios en el país se había intensificado tras el final de la guerra entre Paraguay y la Triple Alianza (1864-1870) y recrudece, sobre todo, durante el gobierno Stroessner, momentos de incentivo gubernamental a la colonización del territorio nacional. Este tipo de acción ha sido estimulada especialmente durante la dictadura la cual promovió la Reforma Agraria y colonización bajo la justificativa de iniciar la expansión de la frontera agrícola en la región oriental del país. Esto se ha realizado con la orientación de un discurso de que los espacios serian "vacíos", áreas de selva "deshabitada" en la que la agricultura traería "progreso" y "civilización". Sin embargo, como ya se mostró anteriormente, la región no estaba deshabitada y sí formaba parte de un vasto territorio indígena, destacadamente de los indios Aché y

\footnotetext{
${ }^{4}$ La afirmación de Borgognon (1968) necesita ser relativizada y situada en su tiempo y contexto histórico porque en temporalidades coloniales se implantaron reducciones jesuíticas en el área correspondiente al actual territorio nacional paraguayo, lo que configura una política oficial colonial en querer administrar el modo de vida de colectivos indígenas.
} 
otros. Esta política oficial llevó a un vaciamiento forzado del espacio para la colonización, con desplazamiento e/o exterminio de las comunidades indígenas. Esta fue una acción de dominación con exclusión de los indígenas como sujetos de derecho y una construcción ideal sobre lo que se desea como Nación; donde se evidencia la eliminación de la cosmologia y del modo de vivir indígena como forma productiva en el espacio y, en contrapartida, se tiene la agricultura mecanizada como único camino de "progreso" para la región.

En ese contexto, Borgognon buscaba dar un panorama general de los pueblos indígenas que vivían en el país en aquel momento, con la expectativa de hacerlos reconocer por la población y el Estado paraguayo, en busca de justicia social. Para el autor, los indígenas componían "una minoría absoluta angustiada por el progreso del país" (BORGOGNON, 1968, p.345). En aquel entonces, en cifras estimadas, dice que los indígenas en Paraguay sumaban 50.000 personas, lo equivalente a 2,5\% de la población paraguaya de la época.

La dictadura de Stroessner fue denunciada por otros muchos estudiosos, como Bartomeu Melià y Mark Münzel, por su abuso de poder y violencia contra los pueblos indígenas. En la actualidad, la "Era Stroessner" es investigada por la Comisión de Verdad y Justicia (CVJ) por los crímenes ejecutados. La CVJ produce un Informe (2014) y retrata la violencia de la época, registro de aproximadamente 500 personas detenidas, además de personas desaparecidas $\mathrm{y} / \mathrm{o}$ ejecutadas extrajudicialmente (asesinadas). Este documento expone que muchas comunidades indígenas y campesinas fueron atacadas en ese tiempo, como forma de limpieza de territorio y de las cuales no se tiene registro exacto. De los delitos cometidos por el Estado, principalmente con relación a los indígenas, dice:

A todo esto se suma la cantidad de niños, niñas, hombres y mujeres de los pueblos indígenas desaparecidos, ejecutados durante la dictadura, sobre los cuales aún no existen cifras oficiales, y que la Comisión de Verdad y Justicia no pudo cuantificar. Sin embargo se concluyó con Crímenes de Lesa Humanidad los hechos de violaciones a los derechos humanos, principalmente a las comunidades Ache, Ayoreo y Toba (INFORME CVJ, 2014, p.4).

Así, la violencia contra las comunidades indígenas está directamente relacionada a la política de expansión de las fronteras agrícolas del país, la cual fue viabilizada por el Estado paraguayo a partir de una colonización oficial en la región fronteriza Oriental. De esta manera, el gobierno implementó una política caracterizada por la violación de derechos e intentos de promover genocidio o etnocidio contra pueblos originarios. El propósito mayor era impulsar el vaciamiento de grandes extensiones de tierra para luego vender las áreas a empresas colonizadoras, principalmente de Brasil. En este contexto, miles de indígenas fueron asesinados o confinados en colonias indígenas, 
categoría jurídica equivalente a la de "terras indígenas" en Brasil. Sobre eso, expone Nickson:

\begin{abstract}
Durante el decenio de 1967-77, el IBR [Instituto de Bienestar Rural] vendió casi la totalidad de las tierras fiscales vírgenes que quedaban en la RFO [Región Fronteriza Oriental], principalmente a altos funcionarios de las Fuerzas Armadas y del Partido Colorado gobernante, a precios fiscales muy inferiores a los precios del mercado. A su vez, estos compradores han revendido a compañías agrícolas brasileras con base en Sao Paulo y Curitiba, logrando como consecuencia considerables ganancias especulativas. Por su lado, los principales latifundistas de la región comenzaron a vender grandes áreas de la tierra bajo su control, casi exclusivamente, también a compañías agrícolas brasileras (NICKSON, 2005, p.233).
\end{abstract}

Se percibe entonces el campo de dominación ejercido por las élites paraguayas sobre el territorio y las poblaciones del país. Esta situación explica, al menos parcialmente, el abuso de poder sobre los indígenas y el uso de su imagen y su exclusión como población de derecho, concomitantemente. En ese sentido, se percibe un colonialismo interno en Paraguay y se entiende que es en ese contexto que se inserta el gobierno dictatorial de Alfredo Stroessner que en consonancia con las acciones de las élites nacionales, emprendió la reciente colonización excluyente de las poblaciones indígenas del país, invisibilizándolas.

Esta realidad es similar a la de otros países de América Latina, como Bolivia y Brasil. En Brasil, Ribeiro (1997) expone la histórica lucha indígena y también campesina contra la lógica colonial, los cuales son excluíos del proceso de construcción de la Nación, mientras Urioste y Kay (2005) exponen la lucha de los indígenas de Bolivia para retomar sus tierras tradicionales. En general, lo que se percibe es una continuación del proceso de colonización, con la forma de colonialismo interno, en los nuevos Estados Nacionales de América Latina. Las élites criollas construyen campos de poder, dominación, exploración y exclusión a partir de la lógica de la acumulación del capital.

En este sentido, De la Peña, a partir de la realidad de México, habla sobre la ciudadanía étnica, la cual "se refiere al reclamo de mantener una identidad cultural y una organización social diferenciada dentro de un Estado, el cual a su vez debe no sólo reconocer, sino proteger y sancionar jurídicamente tales diferencias" (DE LA PEÑA, 1999, p.11). El autor muestra que, al forjar la Nación, los indígenas son relegados al pasado, como sujetos distantes, y así se los vuelve invisible y se les elimina de los espacios nacionales. En ese sentido, habla de la necesidad de las identidades étnicas, que se extinga el paternalismo político y que los espacios públicos se hagan democráticos. En Paraguay, se puede suplantar esa perspectiva, insiriendo a las particularidades de sus pueblos, los cuales todavía no disponen de una organización política activa y siguen en el margen, invisibilizados por la distancia temporal y espacial que se les impone la acción política y social del país. 
Es en ese contexto de invisibilidad de los indígenas que se implementa la Reforma Agraria y la colonización reciente en Paraguay. Se excluyen completamente a los indígenas, expulsándolos o exterminándolos, sin garantirles territorio para su reproducción sociocultural ni seguridad alimentaria. El Instituto de Bienestar Rural (IBR) no hizo una reforma agraria profunda y muchos latifundios quedaron intactos, con muy pocas expropiaciones. Se distribuyeron, en gran parte, áreas de tierra fiscal o que aún pertenecían al gobierno, y muchas familias paraguayas se beneficiaron con ese programa. Sin embargo, el Estado, marcado por la corrupción, hizo una distribución de tierra de forma clientelista, destinándolas a autoridades, políticos, militares, sus familiares, amigos y personas cercanas al poder que no reunían los requisitos para ser beneficiarios de la reforma agraria. Además de que fue en el marco de la reforma agraria que Paraguay abrió sus fronteras para la entrada de (in) migrantes y empresas multi y transnacionales, para que estos nuevos actores se dediquen a la expansión de la agricultura en el país. Lo que se ofrece como resultado hoy, con aproximadamente 50 años de reforma agraria y con más de 12 millones de hectáreas distribuidas, aún existen muchas reivindicaciones de campesinos sin tierra, así como la mitad de la población indígena del país no tiene oficiamente tierra propia. Al mismo tiempo, las empresas transnacionales y los inmigrantes, en su mayoría brasileños, se fijan como propietarios de tierra en el país, sea en la región Oriental, sea en la banda Occidental.

Con el impulso del Estado y la acción transnacional, se transformó la región Oriental de Paraguay con la colonización reciente; especialmente por la implantación de la agricultura mecanizada, lo que cambio física y simbólicamente el territorio. En este contexto, Yaluff (2007) sugiere que la organización económica del territorio paraguayo pasa a responder a lógicas comerciales regionales, vinculadas a la exportación de carne y de soja, lo que hace que la economía nacional sea satélite de intereses externos. Así, el agronegocio en Paraguay supone un reto, tanto para la soberanía nacional como para el equilibrio ambiental y los derechos ciudadanos. Esta afirmación descansa en el hecho de que en Paraguay el $1,6 \%$ de los propietarios son dueños de $79 \%$ de la tierra (VILLAGRA, 2014, p. 114). Al día de hoy, los indígenas herederos de estos procesos están al margen de la reproducción sociocultural y económica de la región.

Frente a este modelo agroindustrial, los campesinos y las comunidades indígenas del oriente paraguayo defienden un tipo de agricultura tradicional que coloca en el centro de su actividad una relación diferenciada al de la "expansión de la producción a toda costa" y entiende el territorio como un centro de desarrollo cultural y no como un mero espacio para la producción de capital. La frontera entre ambos modelos deviene una serie de conflictos no exentos de violencia y explotación que se dan por la asimetría de las relaciones entre poderosos grupos empresariales locales y trasnacionales $y$ comunidades rurales tradicionales (INFORME CJV, 2009, p.20). 
Las poblaciones indígenas residuales a este proceso continúan habitando la región, sin embargo, estigmatizadas y marginadas. Hay pocas áreas reservadas a ellas, sufren presión de los agricultores para que vendan o alquilen sus tierras, continúan siendo expulsadas y, en algunas ocasiones, son juzgadas como "invasoras". Sus modos de vida no son respetados y son juzgados como "perezosos". Los indígenas de la región están, así, en su mayoría, invisibilizados y marginalizados.

En contradicción al discurso de vacío demográfico, el censo indígena apunta la presencia de comunidades nativas en toda la franja fronteriza entre Brasil y Paraguay. Una representación cartográfica oficial de Paraguay (Figura 1) con la indicación de los territorios de pueblos indígenas, sirve para desconstruir la idea de vacío demográfico justificada para la colonización reciente.

Figura 1: Representación cartográfica del Paraguay. Pueblos Indígenas - Comunidades,

Aldeas/Barrios y Núcleos de Familias, 2012.

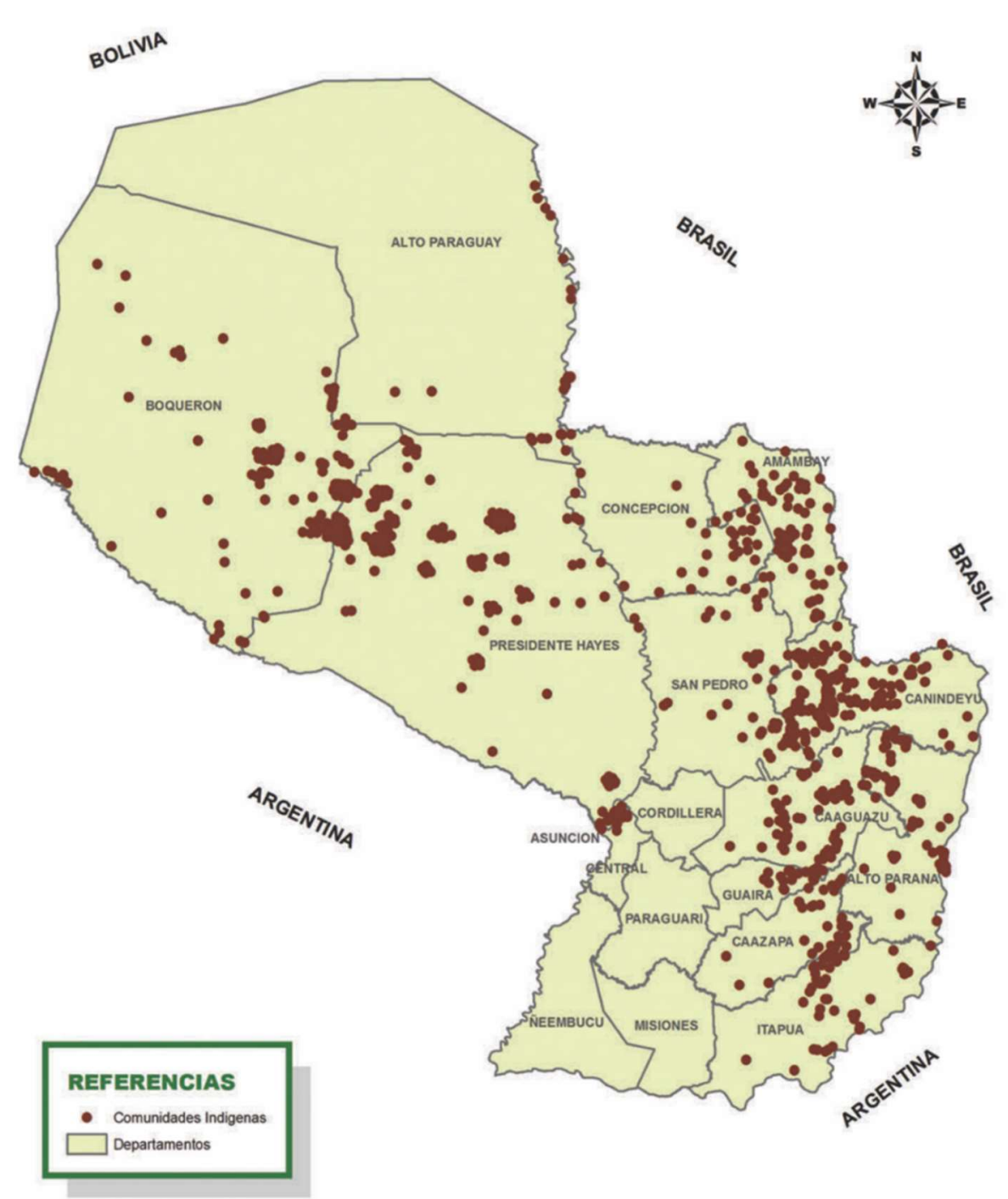

Fuente: DGEEC (2012). 
Por las localizaciones de los pueblos indígenas visualizadas (Figura 1) se infiere que esos fueron aplastados hacia el interior, entre las frentes de colonización que ocurrieron de este a oeste y de oeste a este de la región Oriental. Además, del total de 493 comunidades, el censo de 2012 exhibe que 148 comunidades reportaron problemas de tierra, de las cuales 14 comunidades cuentan con tierra propia, pero no tienen título, y 134 comunidades que no poseen tierra propia. Estos datos muestran que las comunidades todavía no alcanzaron garantizar sus derechos territoriales.

Figura 2: Localización de Santa Rita, Alto Paraná, Paraguay.

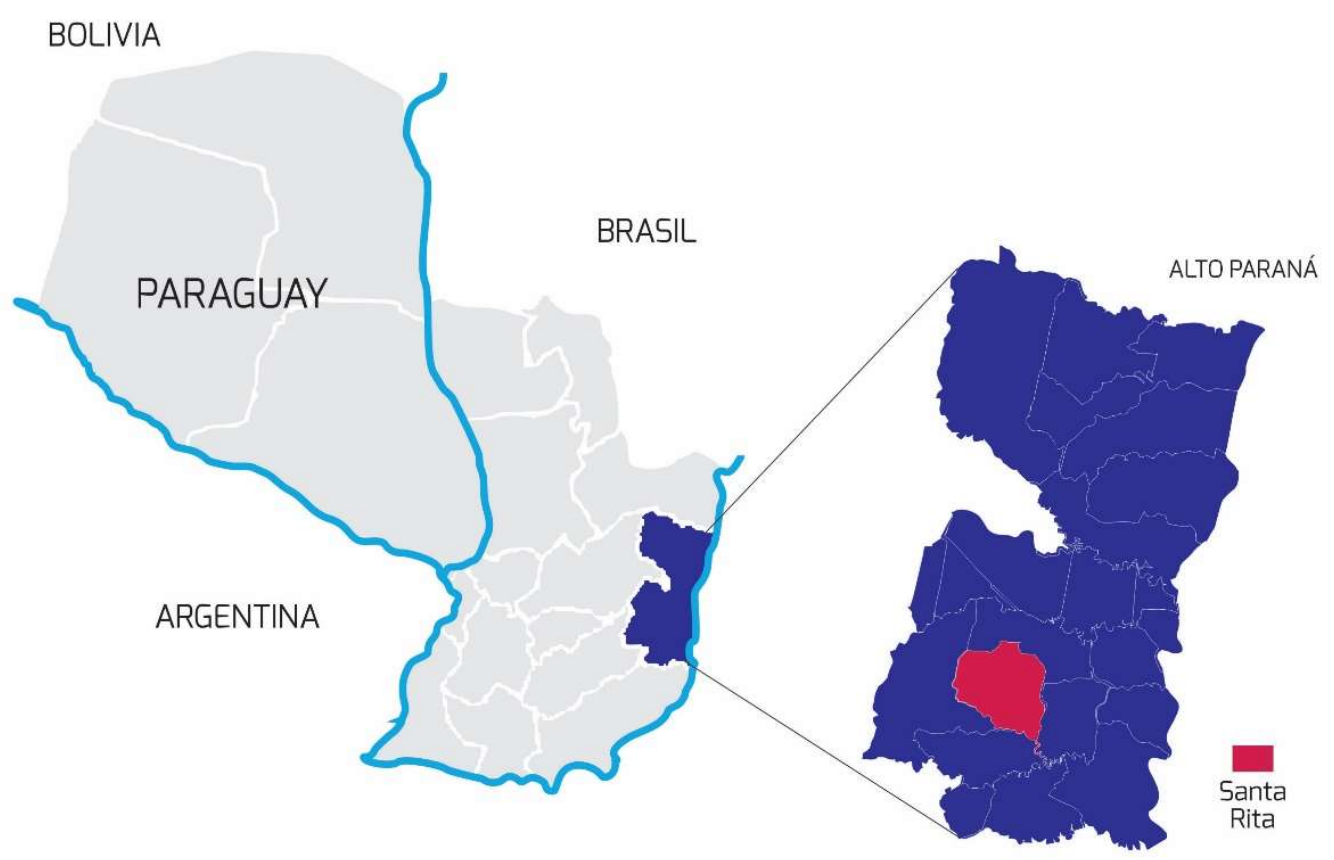

Fuente: Imagen elaborada por los autores.

\section{Exclusión e invisibilidad indígena en Santa Rita}

Este contexto de exclusión e invisibilidad indígena se espeja en la vida cotidiana de la región Oriental en la actualidad. En el trabajo de campo desarrollado ${ }^{5}$ en 2015 en la región - más específicamente en Santa Rita, Alto Paraná - se percibió la marginalización e invisibilidad de los indígenas tanto en los relatos memoriales cuanto en las practicas diarias. Esta es la región con mayor concentración oficial de población inmigrante

\footnotetext{
${ }^{5}$ Andressa Szekut realizó un trabajo de campo por seis meses en Santa Rita. En ese periodo hizo más de 50 entrevistas semi-estructuradas, hizo registros fotográficos, levantó documentos, además de establecer relaciones directas con la sociedad santarriteña, participando de eventos locales, compartiendo y observando las narrativas y prácticas cotidianas de este espacio.

SZEKUT, Andressa; EREMITES DE OLIVEIRA, Jorge. Invisibilidad indígena en la memoria de la colonización reciente de Paraguay. Espaço Ameríndio, Porto Alegre, v. 13, n. 2, p. 41-59, jul./dez. 2019.
} 
en el país y también es la con mayores tasas de expansión de la agricultura mecanizada (ODDONE, 2011). Como resultado de la colonización reciente, Santa Rita tiene una gran concentración de migrantes brasileños y la agroindustria es el mayor rubro económico local, con el área urbana compuesta por servicios que atienden la demanda de ese sector.

Los relatos sobre la presencia indígenas en la región, en la década de 1970, primeros años de llegada de los migrantes brasileños y paraguayos, no pasan de pocos fragmentos memoriales que son mencionados después de mucha insistencia del investigador. Tanto brasileños como paraguayos, repiten la afirmativa de que no existían nativos en la región que eran solo bosques y cuando hacen referencia a los indígenas es como forma de paso, "pasaban por aquí". Mencionan: "no eran de aquí", vivían en el "sertão", en la "selva", en el "mato", "muy lejos". Las pocas menciones surgen para hablar del "exótico" o del "bárbaro", por ejemplo: "Ios nativos comían serpientes" o "no tenían hábito de vestirse"; o surgen, sutilmente, al relatar que al entrar en la selva, "a veces" encontraban indígenas.

Uno de los pocos relatos obtenidos sobre indígenas, en los primeros años de colonización, surge de una anécdota de un migrante brasileño quien cuenta que una de sus hijas, "por ser muito apressada nasceu aqui mesmo, por um curandeiro". Con ese discurso, se le preguntó más sobre ese "curandeiro" y la respuesta fue:

Curandeiro, um índio, um índio do mato. Ele morava lá no sertão do mato e depois veio para a vila, porque ficava mais fácil para ele. Mas bom. Muito bom. Curandeiro, índio, um cacique. E bom pra dar remédio, pra fazer qualquer coisa. Era a única gente que tinha aqui, porque doutor não existia. [...] E ele morava em Cerro Largo.

Incluso ese mismo interlocutor, al ser preguntado a seguir sobre la existencia de indígenas en la región, respondió: "não tinha indígenas aqui, eles moravam no mato". Este discurso contradictorio retrata la presencia de los nativos, a partir de la relación que se tenía con ellos en los primeros años de colonización y la forma en que se los invisibiliza en la memoria local todavía en estos días. Cerro Largo es hoy un barrio rural de Santa Rita y fué una de las primeras villas formadas en la región. Entrevistadas otras personas de esa localidad, no se obtuvieron más informes sobre la presencia de indígenas en el lugar. Se percibe que su presencia es silenciada en los relatos de construcción del espacio y de relaciones sociales, y son relegados a lo distante, lejano en el espacio y en la cultura.

Se presenta esta discusión con el fin de mostrar otra perspectiva histórica, descolonizada que muestre encuadres de memoria entendiéndolos como selección de lo que se quiere recordar, según Pollak(1989) - reproducidos por el Estado y por las poblaciones migrantes que se fijaron en la región. Se trata de una estrategia para la 
(re)constitución de una imagen del territorio, con el propósito de poder colonizar el espacio y alcanzar sus intereses de expansión agro-ganadera. Esta acción fue desarrollada en forma impositiva sobre las poblaciones indígenas y campesinas locales, pues los datos bibliográficos e históricos evidencian que sí existían indígenas esparcidos por toda la región. Toda la región era de bosque, "mato" y selva y fue rápidamente deforestado para la implantación de la agricultura mecanizada ${ }^{6}$. La situación denuncia que los indígenas fueron desplazados, forzosa o "espontáneamente", con la llegada de la colonización.

En la actualidad, según el resultado del censo de las comunidades indígenas de 2012, en Santa Rita existe una comunidad indígena Mbya Guaraní, la comunidad Sapatini, con 64 indígenas. Esta comunidad no aparece en el II Censo Nacional de Población y Viviendas para Pueblos Indígenas 2002, lo que muestra que es de reciente instalación o que antes no era registrada por el censo oficial. Sin embargo, la presencia de indígenas en Santa Rita es negada incluso con la existencia de ese asentamiento urbano en el municipio. Sobre esos indígenas algunos interlocutores dijeron: "Quando chegamos não tinha índio. Eles vieram poucos anos atrás. Quando virou município vieram os indígenas". Y también: "Tem índio porque vem, agora tem muito por aí. E quando tem Expo [Expo Santa Rita, la gran fiesta del agronegocio] eles vêm. Vem vender as coisas deles". En eses y otros muchos relatos recogidos en el trabajo de campo, se percibe la existencia de un flujo de indígenas en el municipio. No sólo de ese asentamiento actual, pero que existieron otros asentamientos que ya fueron desplazados a lo largo de los años. Se nota que el discurso de que en la región no se tenía indígenas contribuye a la negación de la permanencia de indígenas en el municipio en la actualidad y contribuye a la construcción de un discurso en el que ellos aparecen "invadiendo" el espacio. En estos discursos, paradójicamente los migrantes y sus descendientes se presentan como "nativos" y apuntan a los indígenas o originales como "migrantes" de regiones ajenas.

Durante el trabajo de campo aun fueron observados muchos indígenas por el municipio, ellos andaban por la ciudad. Mujeres con niños pedían dinero en las casas y por las calles, pequeños iban a las casas a pedir comida, los jóvenes se sentaban en la parada de ómnibus a mirar el movimiento y algunos andaban colectando objetos en basura. Además, estar por todas partes, evidencia estar incorporados a las actividades del municipio. Sufren estigmatización y son excluidos con diversas justificaciones: "não são de aqui"; "não sabem trabalhar"; "você dá comida e roupa e eles jogam fora"; "têm terras, mas preferem vir pedir dinheiro"; "eles invadiram propriedade particular"; "só fazem bagunça"; "governo ajuda, [levam embora] mas eles voltam". Además de eso, los

\footnotetext{
${ }^{6}$ La deforestación masiva que padeció la región Oriental, durante el proceso de expansión agrícola de los años 1970 a 1990, llevó a las autoridades a promulgar el año 2004 una Ley de Deforestación Cero. Fue entonces cuando empezó la tala sistemática de bosques en la región occidental, para crear nuevas explotaciones ganaderas. Con un incumplimiento sistemático del sistema jurídico, se mantienen las talas de forma irregular y no se conlleva en la mayoría de los casos ningún tipo de acción legal. Se calcula que anualmente la destrucción de los ecosistemas arbóreos y naturales representa el 1,44\% del territorio, lo que sitúa a Paraguay entre los países con mayor deforestación en el mundo (MARTENS, AGUAYO, LÓPEZ et al., 2016, p.13-14).

SZEKUT, Andressa; EREMITES DE OLIVEIRA, Jorge. Invisibilidad indígena en la memoria de la colonización reciente de Paraguay. Espaço Ameríndio, Porto Alegre, v. 13, n. 2, p. 41-59, jul./dez. 2019.
} 
indígenas de la comunidad local son constantemente acusados de estar practicando pequeños delitos, hurtos en casas y negocios. En ese panorama se percibe varias estrategias colonialistas recurridas a la negación, estigmatización y exclusión colectiva de la presencia indígena en la región.

En una visita a la comunidad indígena de Santa Rita se hizo contacto con el cacique, quien habló sobre el grupo. Según él, la comunidad es Mbya Guaraní y está compuesta por aproximadamente 120 personas, éstas vinieron de varias partes, sobre todo de Caazapa, Itapua y Encarnación. Él dijo que vino de Caazapa, donde vivía en una gran comunidad, pero que se repartieron y marcharon porque estaban ocurriendo muchas peleas entre los indígenas, y su grupo decía "no queremos pelear, queremos tranquilidad". La situación histórica indicada muestra cierta fragilidad en las comunidades nativas en el país, que se fragmentan debido a los intereses divergentes de sus poblaciones frente a los conctatos interétnicos. Los Mbya generalmente evitan vivir en ambientes sociales marcados por conflictos entre parientes y entre familias de una misma comunidad; cuando esto ocurre, parte del colectivo suele buscar otros lugares para vivir dentro de territorios conocidos según su historia y cosmología.

Este asentamiento existe hace 6 años y, según él, están en Santa Rita "porque en todos los lados están feas las cosas, aquí tienen servicio. Cualquier cosa, juntar latas, trabajar en el campo". Trabajan con recolección de basura reciclable que revenden a compradores la buscan en la comunidad. Y sobre el trabajo en el campo, el cacique explicó que son diaristas. Todas las mañanas los hombres dispuestos a trabajar esperan a los "patrones" que los pasan a buscar para "trabajar por día"; a veces tiene trabajo para todos, a veces no. Los que se quedan en la comunidad hacen otras cosas, como buscar basura "buena" por la ciudad.

El cacique también explicó que no pretenden quedarse allí en el terreno donde están que es propiedad particular. Quieren un lugar para poder plantar y vivir. Dijo que el intendente municipal prometió un lugar para ellos, "pero nadie está cumpliendo con lo prometido". Dijo que la comunidad de Santa Rita ayuda un poco, con ropa, alimento y trabajo, pero que la municipalidad no ayuda. El lugar donde están viviendo está cerca del centro de la ciudad, una zona baja, con pocas casas alrededor, y un arroyo de agua en el fondo del terreno. Allí lo máximo que consiguen es crear algunos animales, pero no alcanza para producir alimentos. Durante la visita a la comunidad algunos coches llegaron y salieron, en su mayoría para el comercio de la basura reciclable, pero también llegó un coche con donaciones. Lo que hizo percibir que esos indígenas están fijados en el municipio, y no están apenas de paso como es constantemente mencionado por la población.

En este contexto, la cuestión de recibir un área de la municipalidad es bastante problemática, justamente porque de tiempos en tiempos la municipalidad los desplaza a las reservas lejos del área urbana, normalmente en otro municipio, y pronto ellos vuelven a la ciudad. Eso pasa porque en la gran mayoría de las veces ese desplazamiento se hace de manera desorganizada, y hasta forzada, sin tener en cuenta a las 
expectativas de la comunidad indígena, a un área que no atiende a las necesidades de la población, y tampoco tienen apoyo público para la fijación en el nuevo espacio, lo que les hace recurrir al área urbana nuevamente. Por lo que se percibe, tener un espacio para la comunidad es algo de interés del grupo, pero es necesario que se haga en intercambio, donde la comunidad participe del proceso de definición del área. Por lo que se levantó en el trabajo de campo, muchas veces ya se realizaron desplazamientos sin diálogo con la comunidad indígena y además de ser un acto violento que no trae resultados, esta sigue siendo la única alternativa de las autoridades públicas. Ese movimiento muestra además de la exclusión sociocultural, también la búsqueda de invisibilidad del indígena y la legitimación de su marginalidad.

Un aspecto bastante despreciativo para los indígenas, percibido en la región, es la designación de "bugre", término recurrente entre migrantes brasileños y descendientes. Esta nomenclatura que en su origen medieval del francés (bougre) hace referencia al no cristiano o herético (CARDOSO, 2007; GUISARD, 1999), es utilizada históricamente para nombrar a los nativos en la zona de colonización portuguesa, excluyéndolos como no civilizados. Guisard (1999) apunta que existen tres matrices actuantes en el término despreciativo "bugre". La religiosa, la socio-evolutiva y la biológica, cada una de ellas es de descalificación absoluta. Lo que se confirmó en el trabajo de campo, pues se percibió que el termino es utilizado en la región como forma de caracterizar a los indígenas como inferiores - en relación con la población de migrantes y descendientes - por su forma de ser y vivir.

De esa forma, se percibió que la presencia indígena en Santa Rita desagrada a la población no indígena local. No se habla de los indígenas, a menos que se insista y lo que se dice es para estigmatizarlos y excluirlos. En general, lo que se expresa es que los indígenas estorban y la mejor opción es que sean llevados de allí, sin ninguna preocupación con sus derechos o necesidades, sin considerarlos ciudadanos o sujetos de derecho. Esta situación revela una relación conflictiva y excluyente entre la población en general y los indígenas. Y ellos continúan en el municipio, invisibilizados aun estando por todas partes, a merced de los intereses y provecho de los ciudadanos de pleno derecho.

Se recuerda que esta situación de exclusión y marginalidad de los indígenas necesita ser observada de forma amplia en Paraguay. La situación presenciada en Santa Rita es un ejemplo de lo que sucede en gran parte del país, el cual tiene innumerables situaciones deflagradas en su territorio de falta de respeto a los derechos indígenas. Algunos casos fueron juzgados por la Corte Internacional de Derechos Humanos, tales como: Yakye Axa, Sawhoyamaxa y Xákmok Kásek, y nuevos casos fueron llevados a la Organización de las Naciones Unidas (ONU) con la acusación de discriminación estructural en Paraguay ${ }^{7}$. Los casos se remiten, en general, a la reivindicación de territorios tomados y de garantía de

\footnotetext{
Procesos disponibles en: $\quad$ http://www.corteidh.or.cr/docs/supervisiones/yakie 24 06 15.pdf; http://www.corteidh.or.cr/docs/casos/articulos/seriec_214 esp.pdf; http://www.tierraviva.org.py/. Acceso en: $10 /$ oct. $/ 2016$

SZEKUT, Andressa; EREMITES DE OLIVEIRA, Jorge. Invisibilidad indígena en la memoria de la colonización reciente de Paraguay. Espaço Ameríndio, Porto Alegre, v. 13, n. 2, p. 41-59, jul./dez. 2019.
} 
Espaço Ameríndio

derechos, fruto de los procesos de colonización que llevaron al exterminio muchas poblaciones originárias.

Así, en general, los indígenas en Santa Rita no son incorporados en la sociedad, viven al margen. Algunas pocas iniciativas de integración de esa población fueron percibidas, y siempre en el sentido de asistencialismo y asimilación, por medio de donaciones o atención médica, y no de reconocimiento de sus derechos y su cultura.

\section{Conclusión}

Se trabajaron estas perspectivas, como forma de mostrar a través de que relaciones sociales - de poder y explotación - y continuas tentativas de dominación se excluye a los indígenas, invisibilizándolos y marginalizándolos como no ciudadanos en la República del Paraguay, especialmente en el Departamento de Alto Paraná, Distrito de Santa Rita. Se muestra además la construcción histórica ideal de una imagen/memoria que presenta la colonización reciente como una "intervención pacífica" en este "espacio vacío". Sin embargo, existe evidencia que parte de las poblaciones indígenas habitantes de la región fué expulsada y/o diezmada no sólo físicamente; también expulsaron ellas de la imagen de la región y componen apenas una "historia lejana" que no forma parte del actual territorio, ni del tiempo presente.

Esas acciones necesitan ser observadas de forma global y no puntual. Los intereses que llevan a la implantación de un modo de producción capitalista con base en la agricultura mecanizada emanan de poderes locales y transnacionales. Así, se percibe que la dicha ciudadanía y la visibilidad indígena no están garantizadas a partir de su cuantificación y ubicación en el mapa por el censo. Y tampoco es suficiente que los indígenas tengan sus derechos reconocidos por la Constitución Nacional y los tratados internacionales de los cuales Paraguay es signatario, cuando los intereses del Estado están en manos de las élites en el contexto de mundialización del capital. A pesar de todo eso, ellos siguen invisibilizados y marginalizados.

Por último, se espera que este trabajo pueda estimular la realización de otros estudios sobre la situación histórica de los pueblos indígenas en el contexto de la colonización reciente en todo el territorio paraguayo.

\section{Gracias}

Los autores agradecen a Alejandro Raúl González Labale por la revisión crítica al texto originalmente presentado en la XII RAM - Reunión de Antropología del Mercosur, evento realizado en la ciudad de Posadas, Misiones, Argentina, en 2017. 
Espaço Ameríndio

\section{Referencias bibliográficas}

BORGOGNON, J. A. Panorama indígena paraguayo. Suplemento Antropológico de la Revista del Ateneo Paraguayo, Asunción, 3 (1-2), 1968, 341-372.

CARDOSO, W. D. 2007. Do índio ao bugre?. In: II Seminário Sustentabilidade e Povos Indígenas, Campo Grande, 2007.

CARDOSO DE OLIVEIRA, R. A Sociologia do Brasil indígena. Brasília: Editora UnB, 1978.

CONSTITUCIÓN de Paraguay. 1870.

CONSTITUCIÓN de Paraguay. 1992. Disponible en: http://jme.gov.py/transito/leyes/1992.html. Acceso en: 14/ago./2017.

DE LA PEÑA, G. Territorio y ciudadanía étnica en la nación globalizada. Desacatos, México, 1999, (1): 1-16.

DGEEC - DIRECCIÓNGENERAL DE ESTADÍSTICA, ENCUESTAS Y CENSOS. II Censo Nacional de Población y Viviendas para Pueblos Indígenas.Pueblos Indígenas en el Paraguay Resultados Preliminares. Asunción: DGEEC, 2002.

DGEEC - DIRECCIÓN GENERAL DE ESTADÍSTICA, ENCUESTAS Y CENSOS. III Censo Nacional de Población y Viviendas para Pueblos Indígenas. Pueblos Indígenas en el Paraguay Resultados Preliminares. Asunción: DGEEC, 2012.

DIRECCIÓN GENERAL DE VERDAD, JUSTICIA Y REPARACIÓN. Informe de la Dirección General de Verdad, Justicia y Reparación de la Defensoría del Pueblo (DGVJR-DP) de Paraguay Referente a las desapariciones forzadas y ejecuciones extrajudiciales de personas en el Paraguay. Asunción: CVJ, 2014. Disponible en: http://tbinternet.ohchr.org/Treaties/CED/Shared\%20Documents/PRY/INT_CED NHS PRY 18222 S.pdf. Acceso en: 18/ago./2017.

GONZÁLEZ CASANOVA, P. Exploração, colonialismo e luta pela democracia na América Latina. Petrópolis: Vozes; Rio de Janeiro: LPP; Buenos Aires: CLACSO, 2002.

GUERRERO, A. Ciudadanía, frontera étnica y mpulsión binaria. Íconos, Quito, 1998, (4): 112-122.

GUISARD, L. A. M. O bugre, um João-Ninguém: um personagem brasileiro. São Paulo em Perspectiva, São Paulo, 1999, 13(4): 92-99.

INFORME CVJ - COMISIÓN DE VERDAD Y JUSTICIA. Situación de los Derechos Humanos en el Oriente Paraguayo en 2009. Conflicto por la imposición de un modelo cultural y agroindustrial - Departamentos de Cordillera, Paraguari, San Pedro, Concepción y Central. Asunción: CVJ, 2009. Disponible en: 
Espaço Ameríndio

https://investigaccionddhh.files.wordpress.com/2011/12/2situacion_social_y ambiental oriente paraguayo.pdf. Acceso en: 16/ago./2017.

MAKARAN, G. Paraguay: el nacionalismo y sus mitos. México: Centro de Investigaciones sobre América Latina y el Caribe/UNAM, 2014.

MARTENS, J.; AGUAYO, E.; LÓPEZ, X.; ORREGO, R.; SAMANIEGO, M.; ÁVALOS. M.; RÍOS, V.; VARGAS, S. Deforestación e Impunidad: Análisis de la actuación del MinisterioPúblico y del Poder Judicial en los casos de deforestación en la zona del Bosque Atlántico del Alto Paraná (BAAPA). Asunción: INECIP/Arandura Editorial, 2016. Disponible en: http://inecip.org.py/wpcontent/uploads/2016/09/DEFORESTACION-E-IMPUNIDAD-corregido.pdf. Acesso en: 19/ago./2017.

MELIÀ, B.; MÜNZEL, C. Ratones y jaguares. Reconstrucción de un genocidio a la manera del de los Axé-Guayakí del Paraguay Oriental. Suplemento Antropológico, Asunción, 1971, 6 (1-2): 7-53.

NICKSON, R. A. Colonización brasilera en la Región Oriental del Paraguay. In: FOGEL, R.; RIQUELME, M. (Comp.). Enclave sojero, merma de soberanía y pobreza. Asunción: CERI, 2005, p.219-253.

ODDONE, H. Perfil migratorio del Paraguay. Buenos Aires: Organización Internacional para las Migraciones, 2011.

PACHECO DE OLIVEIRA, J. “O Nosso Governo”: os Ticuna e o regime tutelar. São Paulo, Marco Zero/MCT-CNPq, 1988.

PARElladA, A.; BELdí DE ALCÁNTARA, M. L. (Ed.). Los Aché del Paraguay: discusión de un genocídio. Copenhague: IWGIA - Grupo Internacional de Trabajo sobre Asuntos Indígenas, 2008.

POLLAK, M. Memória, esquecimento, silêncio. Estudos Históricos, São Paulo, 1989, 2 (3): 3-15.

RIBEIRO, D. Darcy Ribeiro (1922-1997): homenaje. Cuaderno de Trabajo, Mexico, 2, 1997.

SOUCHAUD, S. Geografía de la migración brasileira en Paraguay. Asunción: Editorial UNFPA, 2007.

SZEKUT, A.; EREMITES DE OLIVEIRA, J. Memória e identidade em um espaço de migração: fronteiras em Santa Rita, Alto Paraná, Paraguai. Revista Eletrônica História em Reflexão, Dourados, 2015, 9: 1-14.

SZEKUT, A.; EREMITES DE OLIVEIRA, J A presença de brasileiros na recente colonização do Paraguai. Mediações: Revista de Ciências Sociais, Londrina, 2016, 21: 303-33. 
Espaço Ameríndio

SZEKUT, A.; EREMITES DE OLIVEIRA, J. "Aquí todos somos migrantes o hijos de migrantes, tanto los brasileños como los paraguayos": memórias de migrantes brasileiros sobre a situação de colonização recente no Distrito de Santa Rita, Departamento de Alto Paraná, Paraguai. Fronteiras: Revista de História, Dourados, 2017, 19: 319-352.

URIOSTE, M.; KAY, C. Latifundios, avasallamientos y autonomías. La reforma agraria inconclusa en el Oriente. La Paz: Fundación Tierra, 2005.

VILlagRA, L. R. La metamorfosis del Paraguay: del esplendor inicial a su traumática descomposición. Asunción: BASE-IS, 2014. Disponible en: http://www.baseis.org.py/wp-content/uploads/2015/07/2014Dic_LaMmetamorfosis.pdf. Acceso en: 29/ago/2017.

YALUFF, Y. Organización económica del territorio paraguayo: integración regional, desintegración nacional. Población y Desarrollo, Asunción, 2007, 33: 83-96.

Recebido em: 19/03/2019* Aprovado em: 17/04/2019* Publicado em: 30/12/2019 